\title{
Knowledge and awareness regarding facemasks among medical professionals in a COVID dedicated hospital - Time for introspection and system strengthening.
}

\section{Sulakshna Aggarwal}

Maulana Azad Medical College

Lovenish Bains ( $\square$ Lovensihbains@gmail.com )

Maulana Azad Medical College

Anurag Mishra

Maulana Azad Medical College

Aashima Dabaas

Maulana Azad Medical College

Madhav Goel

Maulana Azad Medical College

Aiman Afsar Perween

Maulana Azad Medical College

\section{Research}

Keywords: Facemasks, Covid-19, Medical professionals, infection, prevention, knowledge

Posted Date: April 7th, 2021

DOI: https://doi.org/10.21203/rs.3.rs-354540/v1

License: (c) (1) This work is licensed under a Creative Commons Attribution 4.0 International License. Read Full License 


\section{Abstract}

Background- There is a limited literature especially in India on the awareness regarding facemasks among medical professionals. Therefore the aim of the study is to assess the awareness, practices followed and problems faced in using different types of facemasks among medical professionals in a COVID dedicated hospital.

Methodology- An e-survey via was conducted among medical professionals working in a tertiary care (COVID dedicated) hospital of North-India. The survey asked for the general demographic details, knowledge and awareness on facemask use, quality and various problems faced on regular or prolonged use, sanitization / disposal and recommendations to infected and non- infected people in community.

Results- Survey was sent to around 368 medical professionals out of which a total of 150 participants completed the survey giving an overall response rate of $40.8 \%$. The mean score was $9.8+/-2.375$ out of 21 giving an overall correct rate of $46.67 \% .38 \%$ and $31.33 \%$ participants knew the correct recommendations of facemasks to infected and non-infected people in the community respectively, Only $4.67 \%$ knew the correct sanitization procedures, $84 \%$ and $69.33 \%$ participants reported problems of discomfort on face and sweat issues respectively while $48.7 \%$ of the population felt some amount of breathlessness within 1-3 hours with N-95/FFP2 masks.

Discussion- Awareness in this part of the world was low as compared to the western compared to countries $(46.67 \%)$ which increases significantly with years of experience $(p<0.001)$, however no such correlation of knowledge score with discipline of medical professionals was found. Since, it is the young medical force which is at the forefront to tackle the menace, therefore, institute should provide regular training and knowledge up gradation about the facemasks and adequate and accurate information needs to be disseminated to younger medical professionals via social media to prevent them from the risk of infection.

\section{Background}

It is known that person to person transmission is the route for spread of COVID-19 through transmission of droplets by coughing or sneezing of an infected individual. ${ }^{[1,2,3]} \mathrm{WHO}$ has highlighted the role of nonpharmaceutical interventions such as facemasks and hand hygiene as measures to prevent the droplet transmission since influenza pandemic in 2009 till an effective antiviral medication or vaccine comes. [4] Meta-analysis studies showed that use of facemasks among healthcare workers and non- healthcare workers can reduce the transmission of infection by $80 \%$ and $47 \%$ respectively. ${ }^{[5,6]}$ Thereafter it has been stressed to make effective guidelines ${ }^{[7,8]}$ for the proper selection and use of facemasks. Guidelines regarding reuse and sanitization of facemasks have also been issued by Centre for disease control (CDC). ${ }^{[9,10]} \mathrm{Few}$ studies are published in India so as to assess the awareness of COVID 19 among healthcare workers. ${ }^{[11,12]}$ 
However, there is a wide lacuna in literature on the awareness on use of different types of facemasks among medical professionals. Medical professionals are the frontline workers in this deadly situation of pandemic, therefore, accurate knowledge regarding quality and features of facemasks and the correct practices followed by them in using different types of facemasks is of paramount importance so as to prevent transmission and hence reduce people suffering from the infection and keep the country safe. Therefore, we conducted this study to assess the knowledge, practices followed and problems faced in using different types of facemasks among medical professionals in a COVID-19 dedicated hospital.

\section{Methodology}

This cross-sectional survey was conducted among medical professionals working in a tertiary care hospital of North- India. The ethical clearance for the study was obtained from institutional ethics committee. An e-survey was conducted in the month of July and August, when the COVID-19 situation was at the peak in the country. An online questionnaire on Google forms was created. The e-survey URL was circulated via Email and WhatsApp to the medical professionals working in the hospital and 2 reminders were sent at an interval of 2 weeks via Email and WhatsApp. The sample size came out to be 151 in a finite population of 500 upon using the formula SS[1+(1-SS/pop)]. Where SS is the sample size in infinite population which was 216 assuming the prevalence for correct rate of knowledge test among medical professionals $90 \%{ }^{[13]}$ and margin of error of $4 \%$ and confidence interval of $95 \%$,

\section{Questionnaire}

The study questionnaire was divided into 3 sections, the first section asked about the personal information such as designation, discipline, years of experience, level of triage in which they work in the hospital, type of facemask they use etc. The second section consisted of questions which assessed them on the problems they face in using different types of facemasks. The third sections consisted of questions which assessed them on the awareness they have and the right practices followed by them while using different types of facemasks. The correct answers in the questionnaire were allotted points and hence the participants were assessed from a total score of 21 points. The results were calculated and compiled using Microsoft Excel and statistical analysis was done using SPSS (IBM) version 23software. The correlation between the personal details and the score of awareness and right practices followed was done using one-way ANOVA test.

\section{Results}

The questionnaire was sent to 368 doctors working in the hospital. Out of which 150 participants filled the questionnaire so the response rate was $40.8 \%$. Their demographic details are given in table 1 , highest mean score by $6-10$ years of experience $(12.09+/-1.758)$.

Table-1 - Demographic details of the participants. 


\begin{tabular}{|lllll|}
\hline Medical professionals (score out of 21) & & & \\
\hline \multirow{5}{*}{ Experience } & Less than 3 years & $\begin{array}{l}\text { Number of } \\
\text { participants }(\mathrm{N}=150)\end{array}$ & $\begin{array}{l}\text { Mean score +/- } \\
\text { Standard deviation }\end{array}$ & P \\
& 3-6 years & $21(48.67 \%)$ & $9.26+/-2.285$ & 0.001 \\
& 6-10 years & $12(8 \%)$ & $9.45+/-2.762$ & \\
& More than 10 years & $44(29.33 \%)$ & $12.09+/-1.758$ & \\
Discipline & Medical specialty & $57(38 \%)$ & $10.43+/-1.922$ & \\
& Surgical specialty & $63(42 \%)$ & $10.02+/-2.416$ & \\
& Intern & $13(8.67 \%)$ & $10.00+/-2.410$ & \\
& Preclinical/paraclinical & $17(11.33 \%)$ & $9.42+/-2.314$ & \\
Designation & Consultants & $25.3 \%(38)$ & & \\
& Senior residents & $12 \%(18)$ & & \\
& Postgraduates & $19.1 \%(29)$ & & \\
& Junior residents & $12 \%(18)$ & & \\
& Interns and medical \\
& officers & $14.7 \%(22)$ & & \\
\hline
\end{tabular}

The whole survey was allotted maximum points of 21 out of which medical professionals scored a mean score of 9.8 with a standard deviation of 2.375 and hence an overall correct rate of $46.67 \%$. On applying one way ANOVA test, association of score with discipline and years of experience was found. There is a significant relation between the knowledge score and years of experience of the medical professionals. The mean score increases with years of experience $(p<0.001)(F i g-1)$. No significant relation between the knowledge score and discipline of the medical professionals was found suggesting that the awareness regarding correct practices does not depend on the discipline or specialty $(p=0.34)$. (Fig-2)It was found that $74 \%$ of the population uses $\mathrm{N}-95,22.7 \%$ uses 3-ply, $2 \%$ use clothed and some use N-99/100, FFP1, FFP2/FFP3 etc. (Fig-3)

A vast majority of the population (greater than $50 \%$ ) faces the problem of humidity, pressure on nose and ears, sweaty, difficulty in tying and around $50 \%$ of the population thinks that facemasks are costly. (Fig4)Also $17.8 \%$ of the population feels short of breath in less than 1 hour, $48.7 \%$ of the population in $1-3$ hours, $23 \%$ in 4 or more than 4 hours and $10.5 \%$ don't feel short of breath at all. (Fig-5)

Table-2 Correct responses in the survey group. 


\begin{tabular}{|c|c|c|c|c|c|}
\hline & $\begin{array}{l}\text { Correct } \\
\text { responses }\end{array}$ & $\begin{array}{l}\text { Experience } \\
\text { (years) }\end{array}$ & & & \\
\hline \multirow[t]{2}{*}{ Questions } & Total & $<3$ years & $3-6$ & $6-10$ & $>10$ years \\
\hline & $(N=150)$ & $(\mathrm{N}=73)$ & $(\mathrm{N}=21)$ & $(\mathrm{N}=12)$ & $(\mathrm{N}=44)$ \\
\hline \multirow{3}{*}{$\begin{array}{l}\text { 1. What kind of facemask do } \\
\text { you recommend to Non- } \\
\text { infected people in } \\
\text { households/ community. }\end{array}$} & $57(38 \%)$ & $35(47.94 \%)$ & $6(28.57 \%)$ & $4(33.3 \%)$ & $12(27.3 \%)$ \\
\hline & $47(31.33 \%)$ & $14(19.17 \%)$ & $10(47.6 \%)$ & $6(50 \%)$ & $17(38.6 \%)$ \\
\hline & $38(25.33 \%)$ & 14(19.17\%) & $6(28.57 \%)$ & $3(25 \%)$ & $14(31.8 \%)$ \\
\hline \multirow{2}{*}{$\begin{array}{l}\text { 2. What kind of facemask do } \\
\text { you recommend to infected } \\
\text { people in } \\
\text { community/household. }\end{array}$} & $39(26 \%)$ & $18(24.65 \%)$ & $4(19.04 \%)$ & $2(16.67 \%)$ & $15(34.1 \%)$ \\
\hline & $46(30.67 \%)$ & $15(20.54 \%)$ & $9(42.85 \%)$ & $6(50 \%)$ & $14(31.8 \%)$ \\
\hline \multirow{2}{*}{$\begin{array}{l}\text { 3. Do you think } 3 \text { Ply masks } \\
\text { are as effective as N-95 in } \\
\text { clinical settings? }\end{array}$} & $47(31.33 \%)$ & $15(20.54 \%)$ & $5(23.8 \%)$ & $2(16.67 \%)$ & $22(50 \%)$ \\
\hline & $7(4.67 \%)$ & $32(44 \%)$ & $14(66.67 \%)$ & $5(41.67 \%)$ & $20(45.5 \%)$ \\
\hline \multirow{2}{*}{$\begin{array}{l}\text { 4. Do you undergo a fit test } \\
\text { before choosing facemask? }\end{array}$} & $71(47.33 \%)$ & $23(31.5 \%))$ & $11(52.4 \%)$ & $11(91.67 \%)$ & $21(47.7 \%)$ \\
\hline & $66(44 \%)$ & $24(33 \%)$ & $10(47.61 \%)$ & $11(91.67 \%)$ & $18(40.1 \%)$ \\
\hline \multirow{2}{*}{$\begin{array}{l}\text { 5. What do you think is the } \\
\text { life of N-95 in daily use } \\
\text { condition? (in households) }\end{array}$} & $63(42 \%)$ & $38(52.05 \%)$ & $5(23.8 \%)$ & $8(66.67 \%)$ & $26(59.1 \%)$ \\
\hline & $79(52.67 \%)$ & $32(47 \%)$ & $11(57.4 \%)$ & $7(58.33 \%)$ & $19(43.2 \%)$ \\
\hline $\begin{array}{l}\text { 6. How do you dispose your } \\
\mathrm{N}-95 \text { mask in hospital } \\
\text { settings? }\end{array}$ & $76(50.67 \%)$ & & & & \\
\hline \multicolumn{6}{|l|}{$\begin{array}{l}\text { 7. How do you } \\
\text { clean/sanitize your face } \\
\text { mask? }\end{array}$} \\
\hline \multicolumn{6}{|l|}{ 8. What does N-95 mean? } \\
\hline \multicolumn{6}{|l|}{$\begin{array}{l}\text { 9. Which organization } \\
\text { certifies N-95? }\end{array}$} \\
\hline \multicolumn{6}{|l|}{$\begin{array}{l}\text { 10. What does } \mathrm{N} \text {, mean in } \mathrm{N} \text { - } \\
\text { 95over mask? }\end{array}$} \\
\hline \multicolumn{6}{|l|}{$\begin{array}{l}\text { 11. What do you think is the } \\
\text { life if N-95 mask in covid-19 } \\
\text { dedicated clinical } \\
\text { conditions? }\end{array}$} \\
\hline $\begin{array}{l}\text { 12. What is the full form of } \\
\text { FFP? }\end{array}$ & & & & & \\
\hline
\end{tabular}

\section{Discussion}


COVID-19 spreads mainly via droplet transmission. ${ }^{[1]}$ Masks act as a simple barrier that prevents respiratory droplets from reaching others. According to a recent study, use of facemasks by healthcare workers and non- healthcare workers can reduce the risk of respiratory virus infection by $80 \%$ and $47 \%$ respectively. ${ }^{[5]} \mathrm{WHO}$ also promotes the use of facemasks to prevent the spread of infection till a suitable vaccine or drug comes. ${ }^{[4]}$ Therefore masks can act as a significant non- pharmaceutical intervention to prevent infection and break the chain of transmission. Since the menace of the respiratory viral infection was not much due to milder diseases and presence of effective anti-viral drugs and vaccines in pre-COVID times, facemasks and their use was not as popular as during present COVID pandemic due to its deadly nature and lack of anti-viral drugs and vaccines against it, therefore use of facemasks and correct knowledge regarding its use has suddenly became a necessity especially among medical professionals.

The overall correct rate for the medical professionals was $46.67 \%$ which indicates an overall poor awareness amongst medical professionals working in a COVID dedicated hospital of India. This is in accordance with the study done in India in which an overall moderate to poor level of knowledge and practices regarding the use of facemasks was found among medical professionals. ${ }^{[12]}$ Similarly, another study among dental health professionals in India showed that less than one third of the participants recorded high overall score for COVID-19. ${ }^{[14]}$ However, this is in contrast with the study conducted in Mumbai to assess the awareness among healthcare students and professionals on SARS-COV-2 for which the overall correct rate came out to be $71.2 \%$. ${ }^{[15]}$ This might be due to the fact that the above mentioned studies assessed the knowledge on SARS- COV-2 as a whole whereas our study assessed the awareness on only prevention aspect of corona virus disease. This is also in contrast with the study on dentist's awareness and knowledge levels on the novel coronavirus-19 in Istanbul [16] Turkey and a similar study conducted by Tripathi R et al ${ }^{[17]}$ in Saudi Arabia which showed an overall correct rate of $89 \%$. Also a study done in China by showed an overall correct rate on COVID-19 of $89 \%{ }^{[18]}$. Therefore, it can be inferred that there is a strong need to increase awareness among medical professionals especially regarding the use of facemasks because as compared to other countries, the awareness here is pretty low.

On further analysis of this data, it was found that the mean score increases significantly with increase in years of experience; however, no such correlation was found between the awareness score and the discipline of the medical professionals. These findings were corroborated by a similar study in which knowledge score varied significantly with educational status with postgraduates having a higher mean knowledge score than undergraduates. ${ }^{[14]}$ However, Ehladi's study ${ }^{[19]}$ showed no significant correlation between the years of experience and knowledge, but the knowledge varied significantly with the department. This might be because of the differences in the sources of information. The main source of information used in Libya according to the study was TV and social media, however, the main sources of information in our country according to this study is CDC and WHO guidelines. (Fig-6)It might be possible that doctors with more experience are more comfortable and approach more to these guidelines as compared to younger doctors whereas everyone accesses TV and social media on the same rate. 
According to table 2, majority of the medical professionals showed a good knowledge on how to keep facemasks when not in use, ${ }^{[20]}$ reuse practices, ${ }^{[21]}$ and life of N-95 in COVID dedicated conditions. ${ }^{[9]}$ Whereas, very few medical professionals showed a good knowledge on disposal practices, ${ }^{[22]}$ (only $31.33 \%$ participants followed the correct practice of treating the mask with the hypochlorite solution before disposing in the dustbin), portals of entry of COVID-19, ${ }^{[23]}$ recommendations of facemasks to noninfected as well as infected population, ${ }^{[24]}$ and the difference between 3-ply and N-95 in clinical settings. ${ }^{[24]}$ Only $23.7 \%$ participants were aware of the correct practice of reusing the facemask after 3 or more than 3 days but as a policy matter of the hospital, it is disposed off. A few (4.6\%) participants follow the correct practice of sanitizing the facemask with steam or hydrogen peroxide solution.(Table - 2)

A face fit-test should be carried out before people wear respiratory protective equipment for the first time. Inadequate fit-test can reduce the protection provided and exposes the person to the risk of infection and lead to immediate or long-term ill health or can even put the wearer's life in danger. ${ }^{[25]}$ For the proper fit of the respirator, one must need to shave of the facial hair and put the respirator at the correct place on face and press the nose clip so as to ensure no leakage from the respirator, Respirators should have no leaks, however, should be comfortably put and not over tightened. Only $27.4 \%$ of the population undergo fit test, this is in accordance with the study in Sydney, Australia, ${ }^{[26]}$ in which majority of the population are not fit tested properly and are not aware of the hospital policy for the use of facemasks. As medical professionals are the frontline warriors to tackle the menace of this disease, it is clearly the need of the hour to increase the awareness (especially among younger professionals) regarding prevention techniques, therefore more and more information needs to be disseminated to them regarding prevention.

A vast majority of the population faces the problem of difficulty in tying followed by pressure on their face and ears, humidity, not liked by children, sweat and dirt. Around $50 \%$ of the population finds them costly (fig-4). Participants also reported other problems such as acne, skin rash, odor even after brushing well, spectacles become foggy, doesn't provide enough protection over beard, itchy, contact dermatitis, headache speech becomes incoherent etc. This is in accordance with the studies done in Sydney, Australia, ${ }^{[27]}$ Germany ${ }^{[28]}$ and by Letita et al, France ${ }^{[29]}$ during influenza pandemic in which they mentioned several problems faced by general population in using facemasks such as pain, shortness of breath, discomfort, heat and humidity, etc., However, no study was found which assessed problems faced by medical professionals in using facemasks in COVID pandemic till now.

The extent of breathing problems associated with facemasks was determined in a Heowpeuh's study. [30] They assessed objectively the impact of wearing simple and N95 face masks on breathing resistance. The results showed a mean increment of $126, \%$ and $192 \%$ in inspiratory and expiratory flow rates respectively. There was also an average reduction of $37 \%$ in air exchange volume with the use of N95 respirators. ${ }^{[31]}$ Participants also reported that around $49 \%$ of them feel short of breath in 1-3 hours followed by 4 or more than 4 hours (23\%). (Fig-5) Since, the symptoms start coming within 1-3 hours, it can be projected how difficult would it be for them to wear facemasks for 6-8 hours at a stretch. Some suggestions on the solutions for various problems mentioned are listed in table-3. 
Table-3 Suggestion for better knowledge dissemination and increasing awareness.

\section{Suggestions}

1) Adequate training and education must be provided to younger medical professionals regarding adequate use of facemasks.

2) More focus on prevention of COVID must be put apart from dissemination of information on symptoms, diagnosis, treatment, prevalence, vaccine etc.

3) More and more activities around facemasks should be encouraged such as making interesting and easy to learn videos or presentations from the guidelines so that right information reaches mass population and also young doctors find it easy to learn.

4) Necessary steps should be taken to encourage media (TV news) and social media to disseminate adequate and correct information regarding preventive strategies of COVID - 19.

5) More discussion on prevention should be encouraged among friends and colleagues.

6) Experiments and innovations need to be encouraged in order to reduce the various problems in using facemasks without compromising with their effectiveness and make them more comfortable

7) Practices such as disposing the facemask after doffing or when duty is over and not to bring them at home or resting places need to be encouraged

The strength of this study lies in that, first, this is contributing significantly to the wide lacuna of existing knowledge regarding awareness and problems faced in using different types of facemask among medical professionals. This might give the direction in disseminating adequate knowledge in the identified area via those portals of information which can affect significantly to the awareness to the effected population and help in making the country more aware. Second, medical professionals are regularly dealing with the COVID-19 patients, therefore, their correct awareness is of the foremost importance as it may not only prevent them from infection but also motivate them to disseminate correct guidelines into the community as well thus breaking the chain of transmission. Third, this study was conducted in the biggest Covid-19 dedicated hospital of India which treated more COVID-19 patients than any other hospital in the country. Fourth, this study was conducted in the month of July and August when the menace of COVID - 19 was at its peak in the country.

However, this study has few limitations. First, the sample size was moderate with the response rate of $40.8 \%$ which is comparable to the study done in an Italian teaching hospital where response rate was $25 \%{ }^{[31]}$ and a study done on emergency medical service worker where response rate was $68.8 \%{ }^{[32]}$ but less than $85 \%{ }^{[33]}$ and $92 \%,{ }^{[34]}$ which might be due to time constraints. Secondly, participants found the questionnaire very lengthy. Thirdly, non-participation of nursing officers and other staff is also a major limitation as they also contribute significantly to the management of COVID patients.

\section{Conclusion}


The awareness among medical professionals is low (46.67\%). Experienced doctors have a higher mean score, asit increases significantly with years of experience. The frontline workforce comprises of residents and young workforce, their knowledge regarding face-masks is of paramount importance as in the absence of any proven drug or vaccine, it is the measure to prevent any further spread of infection. This young medical force should update them regularly regarding various facemasks through the guideline's competent authorities and professional bodies. The institute should also provide regular training and knowledge up gradation about the facemasks. A proper fit-test and its importance must be realized among medical professionals. Adequate knowledge among young workforce will also promote them in dissemination correct recommendations to community thus overall prevention the spread of infection.

\section{Abbreviations}

WHO- World health organization

CDC- Centre for disease control and prevention

COVID-19- Corona Virus disease 2019

FFP- Filter face piece

$\mathrm{N}-95$ - Not oil proof, bars $95 \%$ of the particles of size $300 \mathrm{~nm}$.

URL- Uniform resource locator

TV- Television

\section{Declarations}

\section{Ethics Approval and consent to participation}

The ethical approval was obtained from the institutional ethics committee of Maulana Azad medical college. Consent for the participation was incorporated in the survey questionnaire, only those who consented were eligible to participate.

\section{Consent for publication}

Consent for the publication was incorporated in the survey questionnaire, only those who consented were eligible to participate.

\section{Availability of data and materials}

Not available.

\section{Competing interest}


The authors declare that they have no competing interests.

\section{Funding}

None.

\section{Authors' contributions}

LB conceptualized the manuscript. SA designed the study, co-ordinated the execution of the study. SA, LB and $M G$ reviewed the literature, analyzed data, and made major contribution to the writing of the manuscript. LB, AM, AD supervised the execution and provided important intellectual contributions to design, co-ordination and analysis of the study. SA, LB, AM, AD, MG and AAP performed final review and editing of the manuscript. All authors have read and approved the final version of the manuscript.

\section{References}

1. World health organization "Modes of transmission of virus causing COVID-19: implications for IPC precautions recommendations"; https://www.who.int/news-room/commentaries/detail/modes-oftransmission-of-virus-causing-covid-19-implications-for-ipc-precaution-recommendations; [Accessed 29 Oct 2020]

2. Centers for Disease control and prevention, "COVID-19 and IPC overview" ; https://www.cdc.gov/coronavirus/2019-ncov/hcp/non-us-settings/overview/index.html; [Accessed 12 Nov 2020]

3. Anderson EL, Turnham P, Griffin JR, Clarke CC. Consideration of the Aerosol Transmission for COVID19 and Public Health. Risk Anal. 2020 May;40(5):902-907.

4. World Health Organization Writing Group, Bell D, Nicoll A, Fukuda K, Horby P, Monto A, Hayden F, Wylks C, Sanders L, van Tam J. Non-pharmaceutical interventions for pandemic influenza, national and community measures. Emerg Infect Dis. 2006 Jan;12(1):88-94.

5. Liang M, Gao L, Cheng C, Zhou Q, Uy JP, Heiner K, et al. Efficacy of face mask in preventing respiratory virus transmission: A systematic review and meta-analysis. Travel Med Infect Dis. 2020 Jul-Aug;36:101751.

6. Offeddu V, Yung CF, Low MSF, Tam CC. Effectiveness of Masks and Respirators Against Respiratory Infections in Healthcare Workers: A Systematic Review and Meta-Analysis. Clin Infect Dis. 2017 Nov 13;65(11):1934-1942.

7. World health organization "Coronavirus disease (Covid-19) advice for the public: When and how to use facemasks.https://www.who.int/emergencies/diseases/novel-coronavirus-2019/advice-forpublic/when-and-how-to-use-masks; [Accessed 5 Nov 2020].

8. Environmental health and safety, University of Washington; "Guidance for facemask use for preventing the spread of COVID-19"; eds.washington.edu; [Accessed 17 Oct 2020] 
9. NIOSH; CDC; "recommended guidance for extended use and limited reuse of N-95 filtering facepiece respirators"; https://www.cdc.gov/niosh/topics/hcwcontrols/recommendedguidanceextuse.html [Accessed 15 Nov 2020]

10. CDC: "Decontamination and reuse of N-95 respirators", https://www.cdc.gov/coronavirus/2019ncov/hcp/ppe-strategy/decontamination-reuse-respirators.html [Accessed 4 Oct 2020]

11. Parikh PA, Shah BV, Phatak AG, Vadnerkar AC, Uttekar S, Thacker N et al. COVID-19 Pandemic: Knowledge and Perceptions of the Public and Healthcare Professionals. Cureus. 2020 May 15;12(5):e8144.

12. Kumar J, Katto MS, Siddiqui AA, Sahito B, Jamil M, Rasheed N, et al. Knowledge, Attitude, and Practices of Healthcare Workers Regarding the Use of Face Mask to Limit the Spread of the New Coronavirus Disease (COVID-19). Cureus. 2020 Apr 20;12(4):e7737.

13. Zhong BL, Luo W, Li HM, Zhang QQ, Liu XG, Li WT et al. Knowledge, attitudes, and practices towards COVID-19 among Chinese residents during the rapid rise period of the COVID-19 outbreak: a quick online cross-sectional survey. Int J Biol Sci. 2020 Mar 15;16(10):1745-1752.

14. Singh Gambhir R, Singh Dhaliwal J, Aggarwal A, Anand S, Anand V, Kaur Bhangu A. Covid-19: a survey on knowledge, awareness and hygiene practices among dental health professionals in an Indian scenario. RoczPanstwZaklHig. 2020;71(2):223-229.

15. Modi PD, Nair G, Uppe A, Modi J, Tuppekar B, Gharpure AS et al. COVID-19 Awareness Among Healthcare Students and Professionals in Mumbai Metropolitan Region: A Questionnaire-Based Survey. Cureus. 2020 Apr 2;12(4):e7514.

16. Sezgin GP, ŞirinoĞluÇapan B. Assessment of dentists' awareness and knowledge levels on the Novel Coronavirus (COVID-19). Braz Oral Res. 2020;34:e112.

17. Tripathi R, Alqahtani SS, Albarraq AA, Meraya AM, Tripathi P, Banji D et al. Awareness and Preparedness of COVID-19 Outbreak Among Healthcare Workers and Other Residents of South-West Saudi Arabia: A Cross-Sectional Survey. Front Public Health. 2020 Aug 18;8:482.

18. Zhang $M$, Zhou $M$, Tang F, Wang $Y$, Nie $H$, Zhang $L$ et al. Knowledge, attitude, and practice regarding COVID-19 among healthcare workers in Henan, China. J Hosp Infect. 2020 Jun;105(2):183-187.

19. Elhadi M, Msherghi A, Alkeelani M, Zorgani A, Zaid A, Alsuyihili A et al 'Assessment of Healthcare Workers' Levels of Preparedness and Awareness Regarding COVID-19 Infection in Low-Resource Settings. Am J Trop Med Hyg. 2020 Aug;103(2):828-833.

20. Medical express, "How should I clean and store my facemaks" https://www.sprig.co.in/collections/connoisseurs-baking-range/products/extract-of-natural-bourbonvanilla-100-ml?gclid=EAlalQobChMI3byWoLSv7wIVqyK3AB1iPA1XEAEYASAAEgKoBfD_BwE ; [ Accessed 21, May, 2020]

21. Mackenzie D. Reuse of N95 Masks. Engineering (Beijing). 2020 Jun;6(6):593-596.

22. WHO, "How to put on, use, take off and dispose of a facemask"? [Accessed 10 Nov 2020]

23. The Indian Express "WHO new guidelines explained: What are the rules around the world for wearing masks?"; https://indianexpress.com/article/explained/face-mask-who-new-rules-coronavirus-covid- 
19-6445864/ [Accessed 6 Nov 2020]

24. Viswanath A, Monga P. Working through the COVID-19 outbreak: Rapid review and recommendations for MSK and allied heath personnel. J Clin Orthop Trauma. 2020 May-Jun;11(3):500-503. doi: 10.1016/j.jcot.2020.03.014. Epub 2020 Mar 26. Erratum in: J Clin Orthop Trauma. 2020 NovDec;11(6):1169-1171. Erratum in: J Clin Orthop Trauma. 2020 Nov-Dec;11(6):1172-1174.

25. Health and safety executive, "Fit testing face masks to avoid transmission during the coronavirus pandemic" ; https://www.hse.gov.uk/coronavirus/ppe-face-masks/face-mask-ppe-rpe.htm ; [Accessed 15 Oct 2020]

26. Chughtai AA, Seale H, Rawlinson WD, Kunasekaran M, Macintyre CR. Selection and Use of Respiratory Protection by Healthcare Workers to Protect from Infectious Diseases in Hospital Settings. Ann Work Expo Health. 2020 Apr 30;64(4):368-377.

27. Maclntyre CR, Cauchemez S, Dwyer DE, Seale H, Cheung P, Browne G et al. Face mask use and control of respiratory virus transmission in households. Emerg Infect Dis. 2009 Feb;15(2):233-41.

28. Suess T, Remschmidt C, Schink SB, Schweiger B, Nitsche A, Schroeder K, et al. The role of facemasks and hand hygiene in the prevention of influenza transmission in households: results from a cluster randomised trial; Berlin, Germany, 2009-2011. BMC Infect Dis. 2012 Jan 26;12:26. .

29. Canini L, Andréoletti L, Ferrari P, D'Angelo R, Blanchon T, Lemaitre M et al. Surgical mask to prevent influenza transmission in households: a cluster randomized trial. PLoS One. 2010 Nov 17;5(11):e13998.

30. Lee HP, Wang de Y. Objective assessment of increase in breathing resistance of N95 respirators on human subjects. Ann OccupHyg. 2011 Oct;55(8):917-21.

31. Moro M, Vigezzi GP, Capraro M, Biancardi A, Nizzero P, Signorelli C et al. 2019-novel coronavirus survey: knowledge and attitudes of hospital staff of a large Italian teaching hospital. Acta Biomed. 2020 Apr 10;91(3-S):29-34. doi: 10.23750/abm.v91i3-S.9419. PMID: 32275264.

32. Vatan A, Güçlü E, Öğütlü A, Kibar FA, Karabay O. Knowledge and attitudes towards COVID-19 among emergency medical service workers. Rev Assoc Med Bras (1992). 2020 Nov;66(11):1553-1559.

33. Bhagavathula AS, Aldhaleei WA, Rahmani J, Mahabadi MA, Bandari DK. Knowledge and Perceptions of COVID-19 Among Health Care Workers: Cross-Sectional Study. JMIR Public Health Surveill. 2020 Apr 30;6(2):e19160.

34. Parajuli J, Mishra P, Sharma S, Bohora KB, Rathour PS, Joshi J et al. Knowledge and Attitude about COVID 19 among Health Care Workers Working in Seti Provincial Hospital. J Nepal Health Res Counc. 2020 Nov 14;18(3):466-471..

\section{Figures}




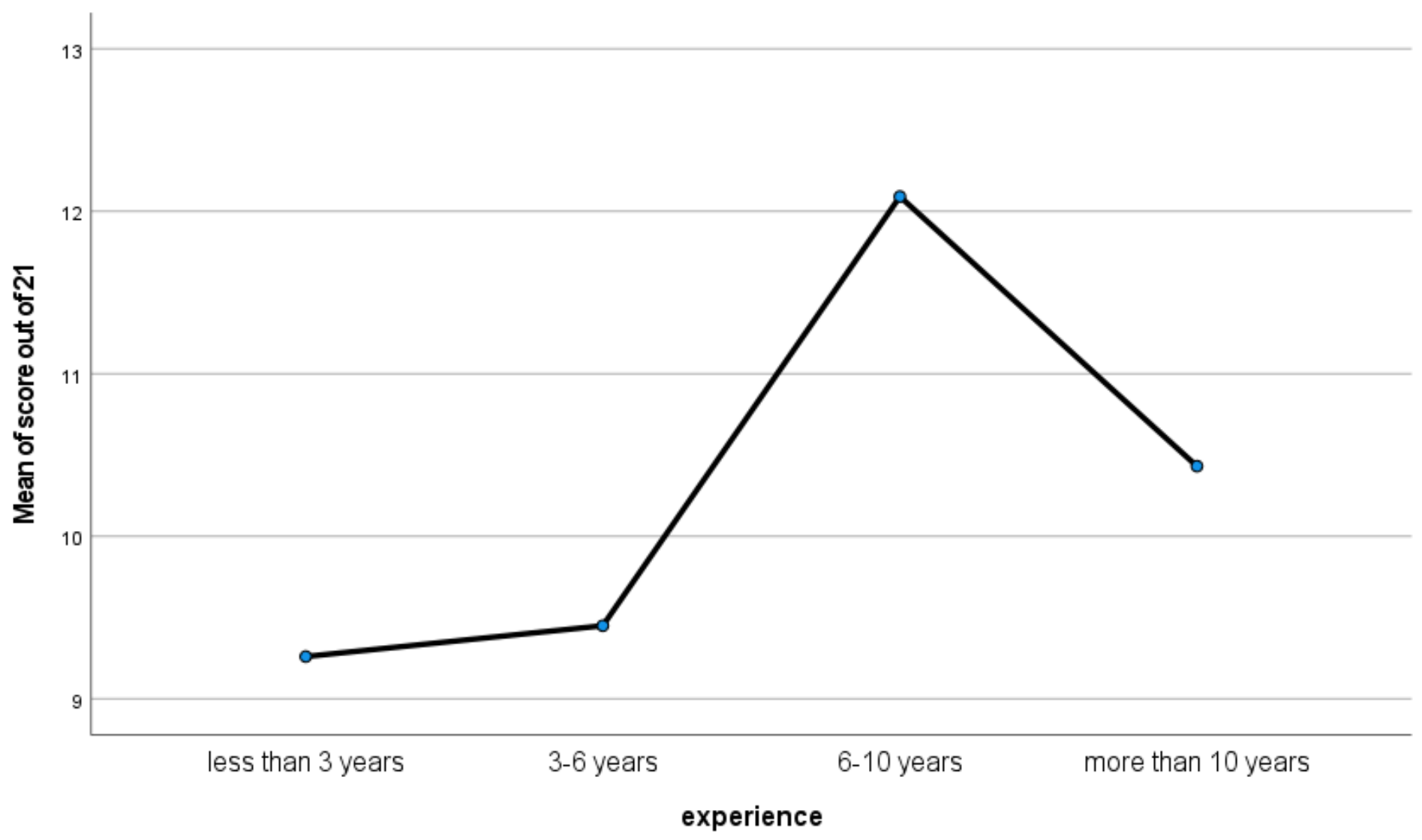

Figure 1

Association of knowledge score with experience (in years)

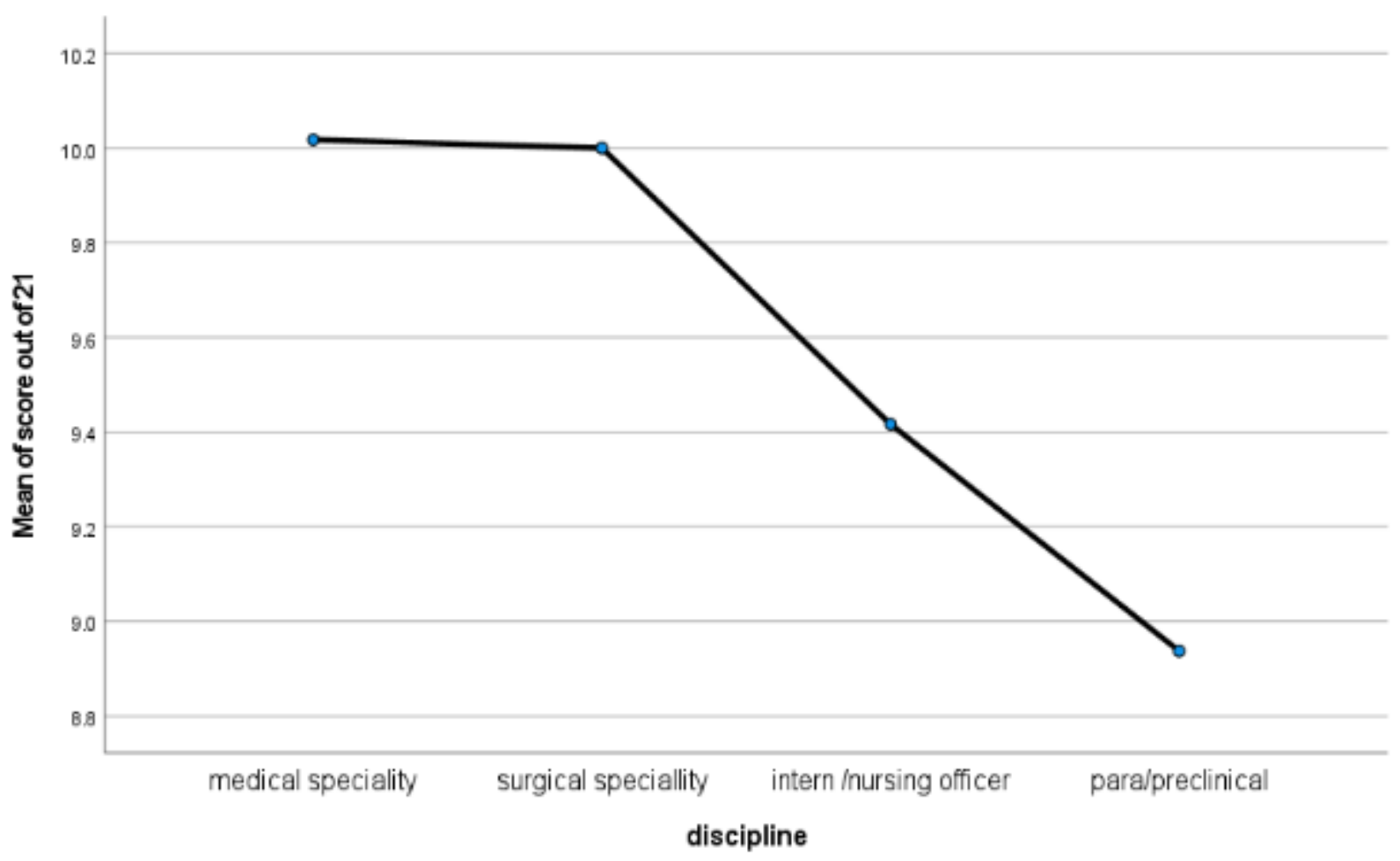

Figure 2 
Association of knowledge score with discipline

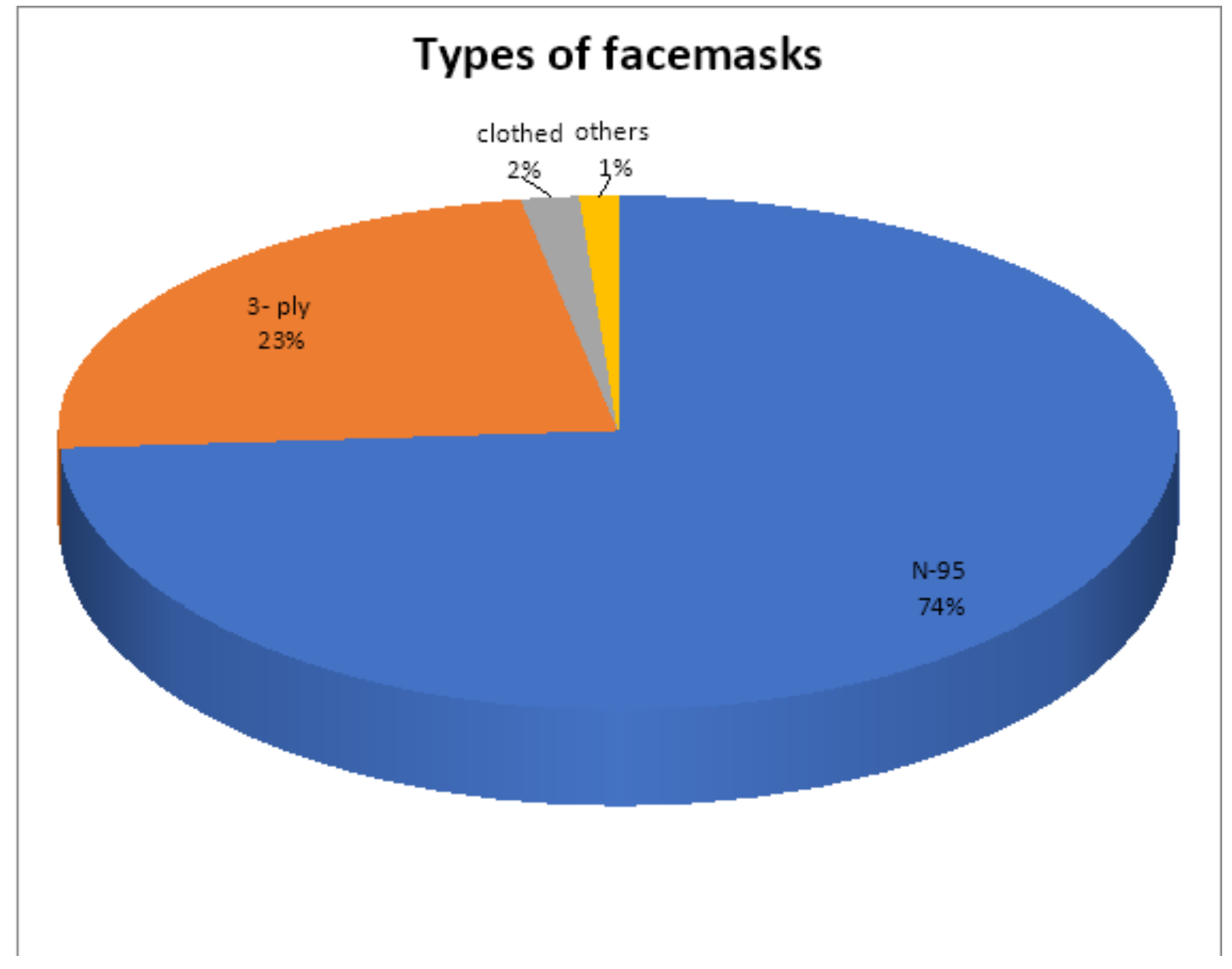

Figure 3

Types of facemasks used by medical professionals. 


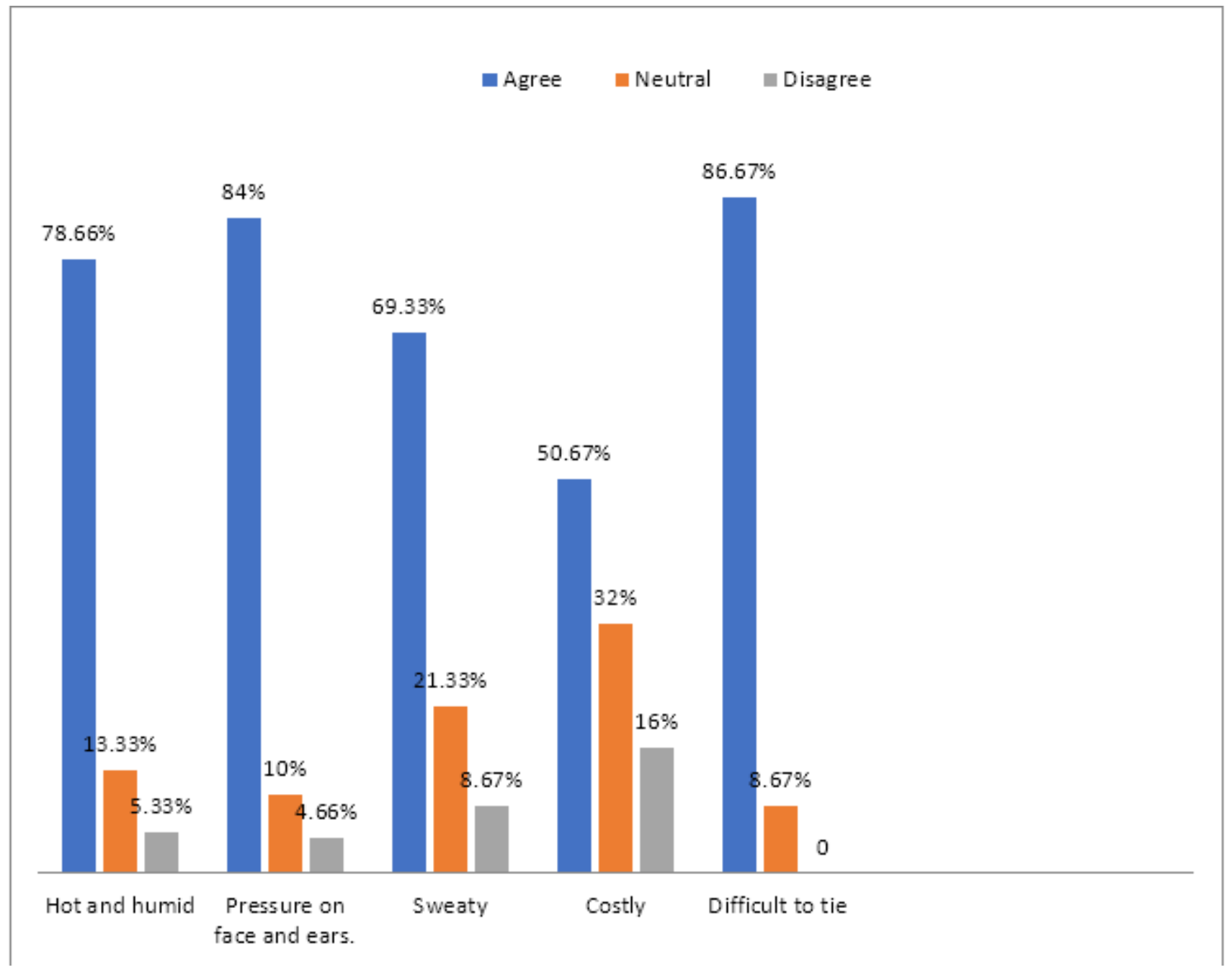

Figure 4

Problems faced in using facemasks. 


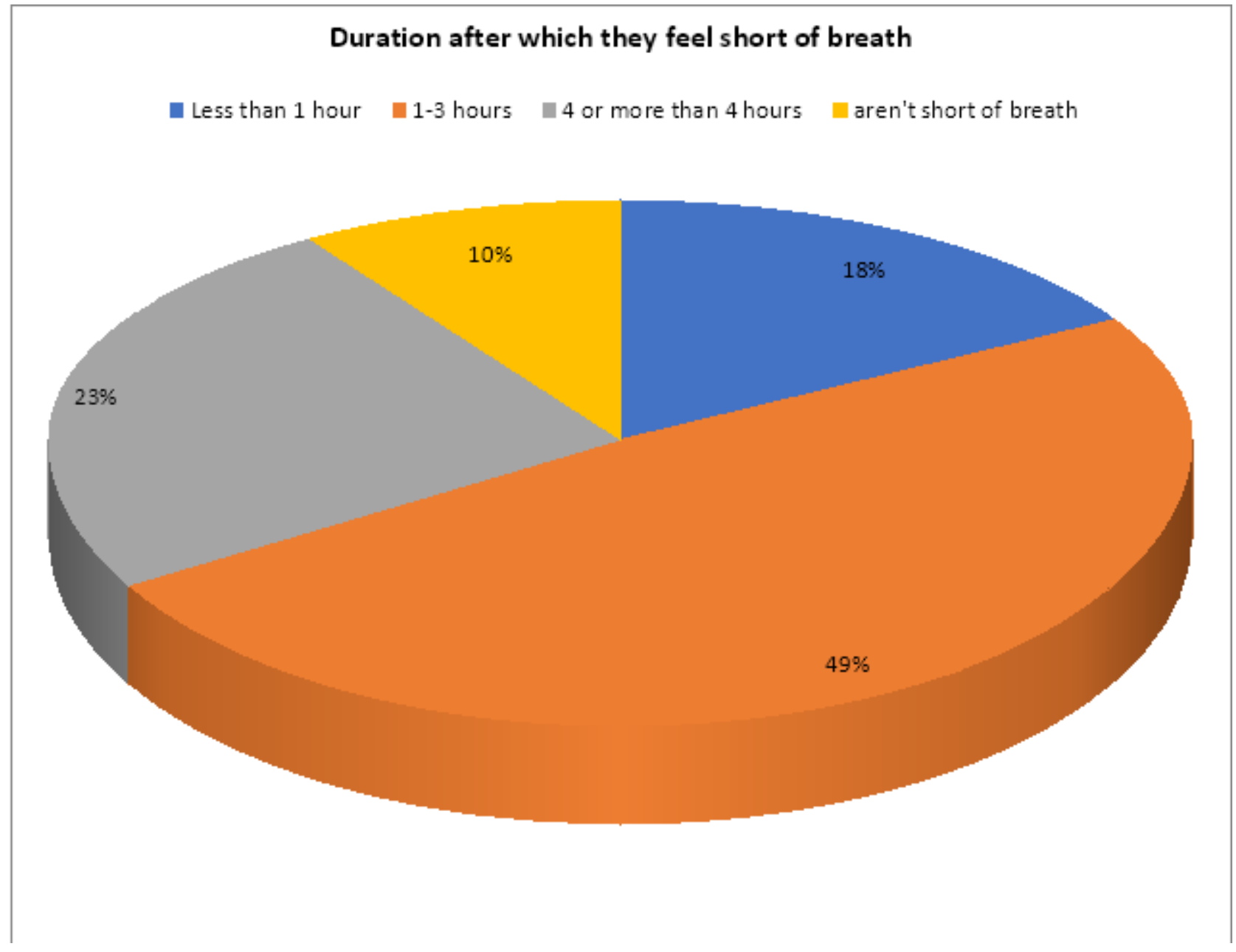

\section{Figure 5}

Duration after which participants feel short of breath.

33. Which guidelines/Information portal do you follow for facemask use?(can choose more than one options)

150 responses

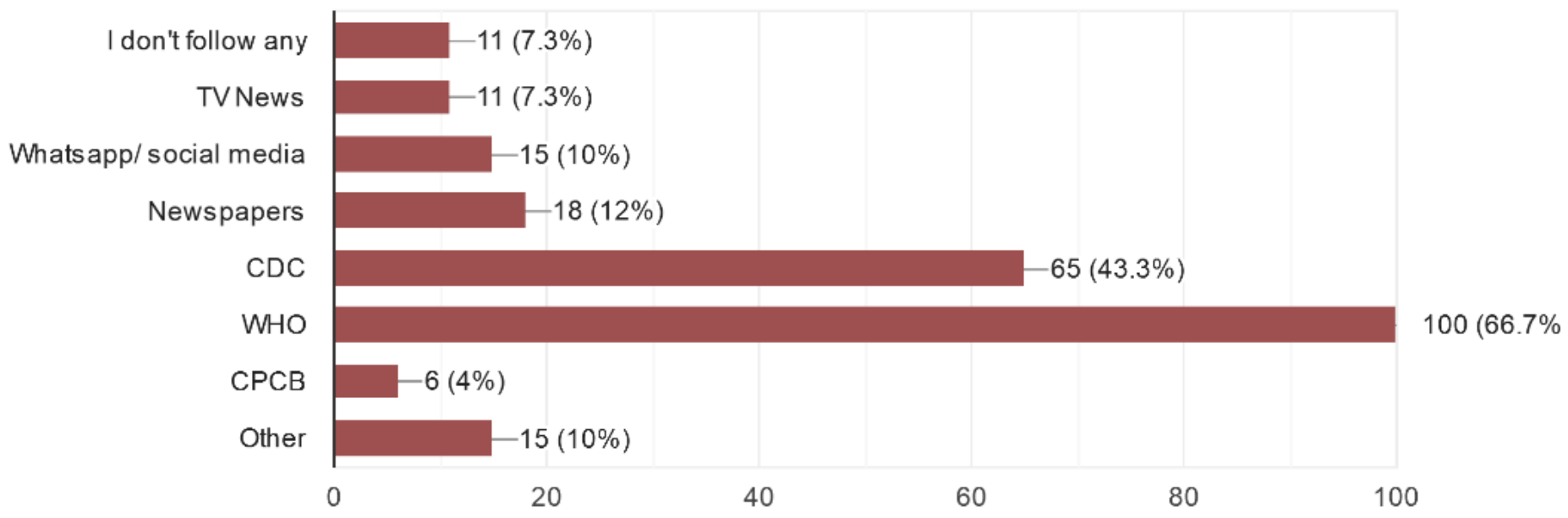


Figure 6

Sources of information used by medical professionals. 